\title{
ADVANCES IN WEATHER FORECASTING
}

T HE introduction into short-range forecasting of the methods of exact science, and the development of long-range forecasting, were the two main topics discussed by Dr. R. C. Sutcliffe, director of research in the Meteorological Office, Bracknell, in a paper read before the Royal Society of Arts on April 15.

Weather forecasting concerns the prediction of the behaviour of the atmosphere; an atmosphere which contains at any one time some 50 depressions or anticyclones and perhaps 100,000 showers, of which 2,000 may be thunderstorms. To observe the weather, there are about 7,000 synoptic reporting stations, 4,000 reporting ships and only 700 stations launching balloons to give measurements of the upper air. Of the latter, moro like 2,000 are needed : a good investment for 100 million dollars to year. In addition the American meteorological satellites now transmit pictures of the clouds seen from above, while a new idea for obtaining upper air data is to use balloons floating horizontally at a fixed density launched from a few strategic sites.

Now, however complicated the motions of the atmosphere may be, they are determined by the laws of physics, and it might have been expected that weather forecasting would have been approached by the methods of exact science in the same way as astronomy. However, because of the many variables and complicated laws the calculations seemed impossibly complex, and until very rocently forecasting remained a skilful art. Even the work of L. F. Richardson forty years ago in showing how to calculate the change in wind and pressure was of no practical value, requiring according to his own estimate 64,000 assistants to keep paco with the changing pattern of the weather.

The introduction of the methods of exact science into short-range forecasting had to await the end of the Second World War. By then, upper air observations had provided a good idea of the three-dimensional structure of the atmosphere; advances were being made in the theory of dynamical meteorology; and the electronic high-speed computer had been invented to replace Richardson's 64,000 assistants. Although work to develop prediction by mathematical calculation started in Britain some five years after that in the United States, by following an independent line Britain's achievement now bears comparison with any country. Dr. Sutcliffe then announced that the method would become routine in the Meteorological Office when a suitable computer was installed later in the year. The system used involves the four available quantities: pressure, temperature, density and the velocity of the air which are related by four laws of fluids,
Boyle's and Charles's law and the conservation of mass. energy and momentum. The data from the observing stations are sorted and analysed by the computer, which interpolates values of the required quantities at a regular network of some 1,500 grid points covering a large geographical area and the depth of the troposphere. The computer then does the calculations and prints out the answers from which the forecast charts can be constructed. A comparison of 102 forecasts in 1963 gave correlation coefficients between forecast and actual height changes at $1,000 \mathrm{mb}$ of 0.71 for conventional and 0.80 for numerical methods; root mean square height errors in metres at $200 \mathrm{mb}$ were 68.5 for conventional and 50.7 for numerical methods. Thus the computer is replacing the skilful forecaster, who will now only be required to predict such things as rain or frost or fog -and this probably only for the present.

The second topic, the long-range forecasting for weeks ahead, is much less of a success story. Public distribution of monthly forecasts by the Meteorological Office began last December, and these aim to give a general statement on how the coming month will work out compared with past averages. Even such a general statement, if reliable, would have very great economic value. The methods of short-range forecasting cannot be extended, since there is an energy loss by friction of 10 per cent every day, and there is no accurate way of calculating either this loss or the energy input. At present, long-range forecasting can be at most a skilful art. The art involves investigating the synoptic situations over the northern hemisphere and trying to find the essential factors that make a month wet or dry, warm or cold. Previous years are then examined for the occurrence of these factors, and it is then inferred that the season will continue to progress in the same way as in these past years. Physical factors such as sea surface temperatures, the state of the polar ice or the Continental snow fields, are also taken into account.

The reasons behind the changeableness of the seasons are unknown. Some relate the cause to sunspots, some to volcanic activity, others to meteoric dust. Dr. Sutcliffo ended by airing his own speculations. As tho seasons go by and the circulation of the atmosphere responds to the changing heat of the Sun, there is no unique sequence of events; but rather there are many possibilities, and as every year begins differently from every other, so it continues differently and there is never a balanced state, always continuous change. The atmosphore is always hunting towards the seasonal balance but never attaining it.

\section{FISHERIES RESEARCH IN JAPAN}

CINCE 1929 there has boon in Japan a Central Fisheries Experimental Station under the Ministry of Agriculture and Forestry. This station was divided, in 1949, with the view of spceding up research, into eight regional laboratories under the Fisheries Agency of the Ministry. The Tokai Laboratory (the Fisheries Research Institute, Tokyo) claims to be the successor of the former Central Fisheries Experimental Station so far as research on marine biology, fishing technology, propagation of marine life and utilization of marine products are concerned. The area served by the Laboratory is theoretically limited to the seas adjacent to the Tokai Region (that is, the central part of tho Pacific Coast of Japan), but its investigations on sardine resources and its oceanographical investigations related to fishing extend into a considerably greater area sinco the Laboratory is a co-ordination centre for the Laboratories of the Agency.

The Tokai Laboratory, undor the directorship of Dr. Takemichi Hidaka, is situated on an approximately threeacre site, on an island of reclaimed land in the estuary of the Sumida River where it enters Tokyo Bay: the Tokyo Wholesale Fish Market is on the opposite bank. Primarily the Laboratory exists for the promotion of Japanese fisheries by investigations and researches into marine resources, and the technical problems of the fishing industry. The second objective is to provide information and 